\title{
Door-to-balloon Time in Cardiovascular Emergency Care in a Hospital of Northern Brazil
} Tárcio Sadraque Gomes Amoras, ${ }^{1,2}$ Taymara Barbosa Rodrigues, ${ }^{1,2}{ }^{\circledR}$ Cláudia Ribeiro Menezes, ${ }^{3}$ Christielaine $^{\circledR}$ Venzel Zaninotto, ${ }^{2 \oplus}$ Roseneide dos Santos Tavares $^{3 \oplus}$

Universidade do Estado do Pará,' Belém, Pará - Brazil

Fundação Hospital de Clínicas Gaspar Vianna, ${ }^{2}$ Belém, Pará - Brazil

Universidade Federal do Pará - Faculdade de Enfermagem, Belém, Pará - Brazil

\section{Abstract}

Background: The use of an adequate door-to-balloon time ( $\leq 90$ minutes) is crucial in improving the quality of care provided to patients with ST-segment elevation myocardial infarction (STEMI).

Objective: To determine the door-to-balloon time in the management of STEMI patients in a cardiovascular emergency department in a hospital of northern Brazil.

Methods: This was a cross-sectional study based on review of medical records. A total of 109 patients with STEMI admitted to the emergency department of a referral cardiology hospital in Pará State, Brazil, between May 2017 and December 2017. Correlations of the door-to-balloon time with length of hospital stay and mortality rate were assessed, as well as whether the time components of the door-to-balloon time affected the delay in performing primary percutaneous coronary intervention. Quantitative variables were analyzed by Spearman correlation and the $G$ test was used for categorical variables. A $p<0.05$ was set as statistically significant.

Results: Median door-to-balloon time was 104 minutes. No significant correlation was found between door-toballoon time and length of hospital stay or deaths, but significant correlations were found between door-to-balloon time and door-to-ECG time ( $\mathrm{p}<0.001)$ and ECG-to-activation (of an interventional cardiologist) time $(\mathrm{p}<0.001)$.

Conclusion: The door-to-balloon time was longer the recommended and was not correlated with the length of hospital stay or in-hospital mortality. Door-to-ECG time and ECG-to-activation time contributed to the delay in performing the primary percutaneous coronary intervention. (Int J Cardiovasc Sci. 2021; 34(1):53-59)

Keywords: Myocardial Infarction; Angioplasty, Balloon, Coronary; Admitting Department, Hospital; Time to Treatment; Quality Indicators; Health Care.

\section{Introduction}

Primary percutaneous coronary intervention (PCI) is the safest strategy for the treatment of ST-segment elevation myocardial infarction (STEMI). ${ }^{1}$ According to the Brazilian Society of Cardiology (SBC) and the American Heart Association guidelines, the time from arrival at the initial hospital to the time of the first balloon inflation during primary PCI, defined as door-to-balloon time, should be within 90 minutes. ${ }^{2}$

In Brazil, adherence to health care guidelines by healthcare centers is still lower than expected, ${ }^{3}$ resulting in a suboptimal performance of these services, compromising the quality of care and safety of patients. ${ }^{2,4}$ Current scientific evidence indicates that adherence to good clinical practice guidelines leads to better performance, reducing morbidity and mortality, length of hospital stay, and costs with STEMI patients, in addition to improve patients' safety and satisfaction. ${ }^{5-7}$

Door-to-balloon time has been used worldwide as an indicator of quality of care, helping to monitor the achievement of aims and goals of health care, ${ }^{3-5}$ foster the strengthening of analytical capacity of the teams involved 
in the management of patients with STEMI and make it as close to ideal as possible. ${ }^{8}$

Therefore, the present study aimed to measure doorto-balloon time and correlate it to the number of deaths and length of hospital stay. We also evaluated whether time intervals of the door-to-balloon time influence on delayed primary reperfusion (wire crossing) at the emergency department of a cardiology hospital in the State of Pará, Brazil.

\section{Methods}

This was a cross sectional cohort study based on review of medical records. Patients of both sexes, aged $\geq 18$ years, with confirmed diagnosis of STEMI were included. All patients had undergone reperfusion within 12 hours after precordial pain and were hospitalized at the emergency department of Gaspar Viana General Hospital Foundation (FHCGV) between May and December 2017. The HCGV is a referral center for heart disease in Pará, Brazil, and the only public hospital for medium and highly complex heart diseases, heading the health care line of myocardial infarction patients among the 144 cities of the state. A total of 109 patients were included in the study.

The following data and variables were systematically collected: age, sex, ethnicity, geographic origin, risk factors, length of hospital stay, number of deaths, and door-to-balloon time and its components.

Since May 2017, to monitor the quality of care provided to STEMI patients in FHCGV, door-to-balloon time and its component times have been prospectively measured using a checklist completed by the staff. The following times were measured: door-to-ECG time $(\Delta t 1)$, time between the electrocardiography test (ECG) and activation of an interventional cardiologist $(\Delta t 2)$ (ECG-to-activation time), time for patient preparation (activation-to-patient preparation) $(\Delta \mathrm{t} 3)$, time between patient preparation and beginning of reperfusion $(\Delta \mathrm{t} 4)$, time between beginning of reperfusion and balloon inflation $(\Delta \mathrm{t} 5)$, time between activation and arrival of an interventional cardiologist at the cath laboratory $(\Delta \mathrm{t} 6)$ (Figure 1).

Data collection was conducted after the study was approved by the Ethics Committee of the FHCGV (approval number 2.527.630).

\section{Outcome Measures}

Door-to-balloon time was described as a numerical variable and defined as a primary outcome. The proportion of patients with adequate door-to-balloon time ( $\leq 90$ minutes), and the components $(\Delta t)$ of the doorto-balloon time were registered as secondary outcomes.

Door-to-balloon time was defined as the time from patient's arrival at the hospital to the time of mechanical reperfusion of the culprit coronary artery. The first balloon inflation during the primary PCI. "Door" was defined as the time of registration of the patient in the emergency department. "Balloon" was defined as the exact time of mechanical reperfusion of the coronary artery during PCI, determined by the interventional cardiologist.

\section{Statistical Analysis}

Statistical analysis was performed using the Statistical Package for the Social Sciences (SPSS) software, version 22. Continuous variables with normal distribution were described as mean and standard deviation and

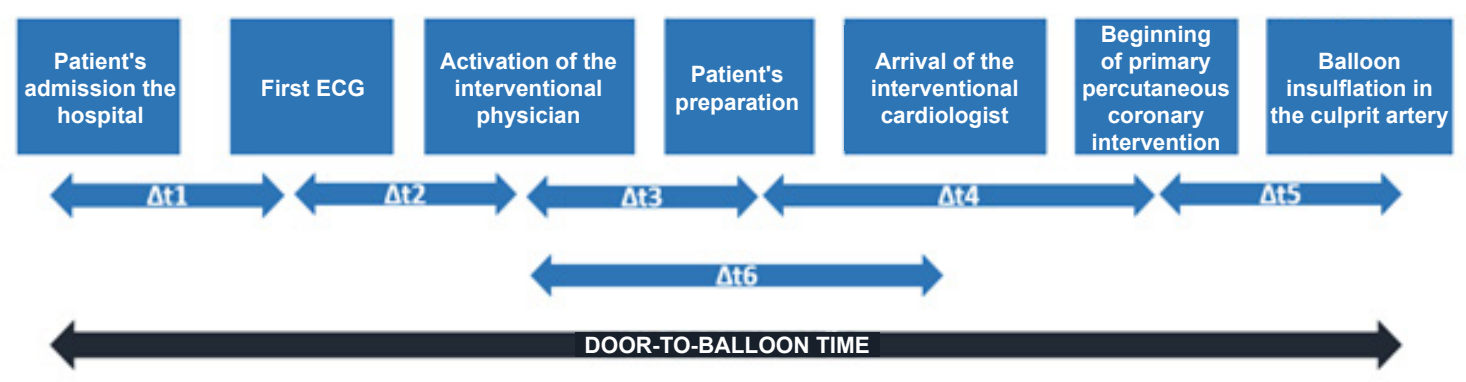

Figure 1 - Representation of the events in the management of patients with acute myocardial infarction with ST-segment elevation, the door-to-balloon time and its components $(\Delta t)$ 
those without a normal distribution were described as median and interquartile range. Normality of data distribution was verified using the Kolmogorov-Smirnov test. Associations between variables were assessed by Spearman correlation (for quantitative variables) and the G-test for categorical variables. The G-test was chosen as it makes no assumptions about the size of the classes. The level of significance was set at 5\%.

\section{Results}

\section{Characteristics of the Sample}

Most patients (78.9\%) were male; $64.2 \%$ self-identified as "pardo". Mean age was $61 \pm 10.88$ years and $69.7 \%$ came from the metropolitan area of the city of Belem, Brazil. Among the risk factors for acute myocardial infarction, $63.3 \%$ of patients were hypertensive, and

\begin{tabular}{lc}
\hline \multicolumn{2}{l}{ Table 1 - Characteristics of the sample } \\
\hline Variables & N = 109 \\
\hline Sociodemographic data & \\
\hline Age (years) & $61.11 \pm 10.879$ \\
\hline Male sex & $86(78.9 \%)$ \\
\hline Pardo ethnicity & $70(64.2 \%)$ \\
\hline Metropolitan area of Belem (origin) & $76(69.7 \%)$ \\
\hline Risk factors & $69(63.3 \%)$ \\
\hline Arterial hypertension & $58(53.2 \%)$ \\
\hline Smoking & $46(42.2 \%)$ \\
\hline Alcohol consumption & $32(29.6 \%)$ \\
\hline Diabetes mellitus & $10(9.2 \%)$ \\
\hline Infarction presentation & $9(8.3 \%)$. \\
\hline Symptom duration on admission (hours) & $7.77 \pm 11.94)$ \\
\hline Anterior wall infarction & $49(45 \%)$ \\
\hline Anterior descending artery occlusion & $54(49.5 \%)$ \\
\hline Right coronary artery occlusion & $41(37.6 \%)$ \\
\hline Circumflex artery occlusion & \\
\hline Deaths & \\
\hline Length of hospital stay (days) & \\
\hline presented as mean \pm standard deviation or number (percentage) \\
\hline
\end{tabular}

$53.2 \%$ of the sample were smokers. Mean time from symptom onset to hospital arrival was approximately $6 \pm 3.116$ horas. In $48.4 \%$ of the cases, there was lesion of the anterior wall. In-hospital mortality was $8.3 \%$ and mean length of hospital stay was $7.77 \pm 11.94$ days. Other clinical characteristics are listed in Table 1.

Mean and median door-to-balloon time was $115 \pm 55.3$ minutes and 104 minutes, respectively. Time components of the door-to-balloon time are described in Table 2.

Median door-to-balloon time was 121 minutes and 78 minutes for those cases where door-to-balloon time was > 90 minutes $(62.4 \%)$ and $\leq 90$ minutes (37.6\%), respectively (Figure 2).

Both door-to-ECG time $(\Delta \mathrm{t} 1)$ and ECG-to-activation time $(\Delta \mathrm{t} 2)$ were significantly correlated $(\mathrm{p}<0.001)$ with door-to-balloon time. No statistical correlation was found between door-to-balloon time and length of hospital stay or in-hospital mortality.

\section{Discussion}

In the present study, most patients with STEMI were male. According to current evidence, cardiovascular diseases are more prevalent in men than women. ${ }^{1,3}$ In addition, men tend to seek medical care less often than

Table 2 - Door-to-balloon time and its components in the management of patients with acute myocardial infarction with ST-segment elevation. Time in minutes, presented as median and interquartile range (IQR) $(n=109)$

\begin{tabular}{lc}
\hline Time intervals & $\begin{array}{c}\text { Median } \\
\text { (IQR) }\end{array}$ \\
\hline Door-to-balloon time & $104(18-133)$ \\
\hline Door-to-ECG time $(\Delta \mathrm{t} 1)$ & $11(5-18)$ \\
\hline ECG-to-activation time $(\Delta \mathrm{t} 2)$ & $10(5-18)$ \\
\hline Activation-to-patient preparation time $(\Delta \mathrm{t} 3)$ & $10(5-15)$ \\
\hline Patient preparation-to-PCI initiation time $(\Delta \mathrm{t} 4)$ & $15(0-45)$ \\
\hline PCI initiation-to-balloon time ( $\Delta \mathrm{t} 5)$ & $20(0-30)$ \\
\hline $\begin{array}{l}\text { Activation-to-arrival of the interventional } \\
\text { cardiologist }(\Delta \mathrm{t} 6)\end{array}$ & $25(0-38)$ \\
\hline $\begin{array}{l}\text { Source: Statistical database of the Cardiology Department of Gaspar } \\
\text { Viana General Hospital Foundation between May and December, 2017. } \\
\text { PCI: percutaneous coronary intervention }\end{array}$ \\
\hline
\end{tabular}




\section{$70,00 \%$}

$60,00 \%$

$50,00 \%$

$40,00 \%$

$30,00 \%$

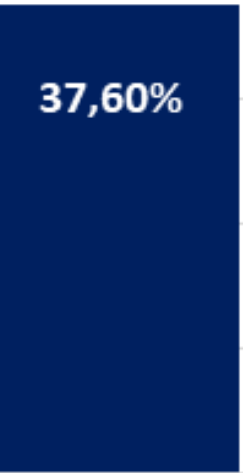

$\leq 90$ minutes

\section{$62,40 \%$}

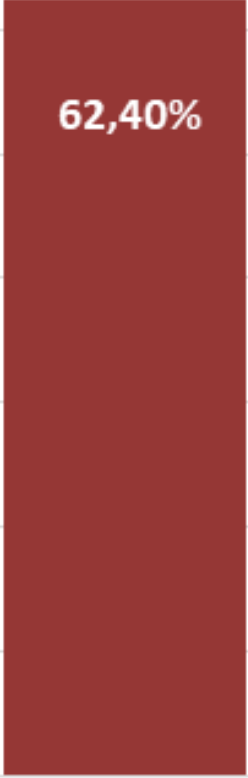

$>90$ minutes

Figure 2 - Distribution of patients according to Door-to-Balloon Time $>$ or $\leq 90$ minutes, Belém-Pará, $2018(\mathrm{n}=109)$

Source: authors. 2018.

Table 3 - Correlation between door-to-balloon time and its components $(n=109)$

\begin{tabular}{|c|c|c|}
\hline Components of the door-to-balloon time & Spearman correlation coefficient & p-value ${ }^{*}$ \\
\hline Door-to-ECG time $(\Delta \mathrm{t} 1)$ & 0.535 & $<0.001$ \\
\hline ECG-to-activation time $(\Delta \mathrm{t} 2)$ & 0.521 & $<0.001$ \\
\hline Activation-to-patient preparation time $(\Delta t 3)$ & -0.005 & 0.961 \\
\hline Patient preparation-to-PCI initiation time $(\Delta \mathrm{t} 4)$ & 0.130 & 0.209 \\
\hline PCI initiation-to-balloon time $(\Delta \mathrm{t} 5)$ & 0.168 & 0.103 \\
\hline Activation-to-arrival of the interventional cardiologist $(\Delta t 6)$ & 0.085 & 0.385 \\
\hline \multicolumn{3}{|c|}{$\begin{array}{l}\text { Source: Statistical database of the Cardiology Department of Gaspar Viana General Hospital Foundation between May and December 2017. PCI: } \\
\text { percutaneous coronary intervention; * Spearman correlation }\end{array}$} \\
\hline
\end{tabular}


women, due to greater difficulty in identifying and facing possible health problems, in accepting changes in lifestyle and talking about problems. Therefore, in general, instead of seeking preventive medical services, men go to the doctor when disease is already established and there is little chance of recovery, leading to irreversible changes in health and quality of life. ${ }^{9,10}$

Age of the study population ranged from 60 to 69 years, with mean of $61 \pm 10.88$ years. Studies have shown that this is the age range of patients who suffer an acute myocardial infarction, due to development of atherosclerotic plaque on the coronary artery wall. Development of early fibroatheroma starts in adolescence and second decade of life and continues throughout life. Advanced atheroma occurs in individuals older than 55 years of age. At this stage, a thin fibrous cap, formed by the activity of proteolytic enzymes, may rupture, exposing the thrombogenic arterial wall, leading to thrombosis. ${ }^{11}$

Hypertension, smoking, alcohol consumption and diabetes mellitus were identified as risk factors for acute myocardial infarction. This is in line with the results reported by a regional study by Costa, ${ }^{12}$ showing that $71.6 \%$ of patients with acute myocardial infarction had hypertension, $71.5 \%$ were smokers or ex-smokers, and $45.5 \%$ had diabetes mellitus. Also, in a nationwide study on STEMI patients by Wang et al., ${ }^{3}$ the main modifiable risk factors identified were hypertension $(78.8 \%)$, dyslipidemia (57.9\%) and diabetes mellitus (37.5\%), among others.

Modifiable risk factors such as systemic arterial hypertension, diabetes mellitus, smoking habit, dyslipidemia, obesity, alcohol consumption and psychosocial distress are more common in individuals with lower socioeconomic status; among the indicators of socioeconomic status, educational attainment is the one with the best correlation with the frequency and severity of cardiovascular risk factors. ${ }^{13}$

Door-to-balloon time was longer than the recommended (90 minutes) in $62.4 \%$ of the cases. In a multicenter study conducted in public and private hospitals in Brazil, Wang et al., ${ }^{3}$ found that $64.04 \%$ of 633 patients with STEMI showed a door-to-balloon time longer than 90 minutes. Dharma et al., ${ }^{14}$ in a study carried out in Jakarta, Indonesia, reported that $51.3 \%$ of 263 STEMI patients had an inadequate door-to-balloon time. These findings emphasize the difficulty in achieving a satisfactory door-to-balloon time in the management of STEMI patients.
More successful results in door-to-balloon time were detected in studies performed in centers where this parameter has been studied for a longer time, as in the United States, Europe and Asia. ${ }^{5,15,16}$ More challenging targets such as a door-to-balloon time shorter than 60 minutes ${ }^{17}$ were achieved by some authors such as Mentias et al., ${ }^{18}$ who reported a median door-to-balloon time of 38 minutes.

Different from other Brazilian studies, ${ }^{4,11}$ the present study did not show the relationship of door-to-balloon with length of hospital stay and mortality rate. For example, Moreira et al., ${ }^{4}$ investigated the correlation of hospital costs and other variables with the doorto-balloon time ( $\mathrm{n}=141$ patients) and did not find any significant difference in the mean length of hospital stay or clinical outcomes between the groups with a door-to-balloon time longer than 90 minutes and those with a door-to-balloon time shorter than 90 minutes. Santos et al., ${ }^{19}$ evaluated the quality of care provided to patients with acute coronary syndrome (ACS) at the emergency department and did not find an association between the quality indicators for ACS (including the door-to-balloon time), and occurrence of complications or death. However, different findings have been reported in international studies, indicating that a reduction in the door-to-balloon time reduces the length of hospital stay, the risk of in-hospital mortality, and even post-discharge mortality at 30 days, one year and three years. 7,16,18,20,21

Regarding other component times of the door-toballoon time that may have influenced the primary outcome, door-to-ECG time $(\Delta \mathrm{t} 1)$ and ECG-to-activation time $(\Delta \mathrm{t} 2)$ showed a significant correlation $(\mathrm{p}<0.001)$ with door-to-balloon time. These two intervals represent the first in-hospital stages of care provided to STEMI patients, and in our sample, they contributed to the delay in primary mechanical reperfusion. Some studies have pointed out that delays in emergency services are associated with difficulties related to the staff, equipment and facility, impaired communication in the hospital setting, and lack of priority care. ${ }^{5,8,22}$

Campos et al., ${ }^{5}$ showed a reduction in door-to-balloon time from 144 minutes to 70 minutes after implementation of a communication code, a 24-hor screening protocol and presence of a cardiologist at the emergency department of the hospital. Also, pre-hospital electrocardiogram, improvement in the communication between the emergency staff and interventional cardiologists and use of technology in patient data transmission, early activation and direct transfer to the cath laboratory result in a significant reduction in the door-to-balloon time..$^{23-26}$ 
This study put the time-to-door time on view; however, its limitation was the fact that it was a one-center study, which limits the generalization of the results.

\section{Conclusions}

In our study, door-to-balloon time in the management of STEMI patients was longer than recommended. We did not find a correlation of the door-to-balloon time with the length of hospital stay or in-hospital mortality rate. Doorto-ECG time and ECG-to-activation of a cardiologist contributed to a delay in mechanical reperfusion. These findings indicate the need for monitoring the time components of the door-to-balloon time in the management of STEMI patients in order to reduce the obstacles to a timely coronary intervention by PCI. In this way, proper measures can be implemented to achieve an adequate door-to-balloon time, according to current guidelines on STEMI, thereby promoting a high quality of care to these patients.

\section{Author Contributions}

Conception and design of the research: Amoras TSG, Menezes CR, Zaninotto CV. Acquisition of data: Amoras TSG Analysis and interpretation of the data: Amoras TSG, Menezes CR, Zaninotto CV, Rodrigues TB, Tavares RS.

\section{References}

1. Santos ES, Trindade PHDM, Moreira HG. Tratado Dante Pazzanese de Emergências Cardiovasculares. São Paulo: Atheneu;2016.

2. Piegas LS, Timerman A, Feitosa GS, Nicolau JC, Mattos LAP, Andrade MD et al. V Diretriz da Sociedade Brasileira de Cardiologia sobre Tratamento do Infarto Agudo do Miocárdio com Supradesnível do Segmento ST. Arquivos Brasileiro de Cardiologia

3. Wang R, Neuenschwander FC, Filho AL, Moreira CM, Santos ES, Reis HJL, et al. Uso de Intervenções Baseadas em Evidências na Síndrome Coronária Aguda - Subanálise do Registro ACCEPT. Arq Bras Cardiol.2014;102(4):319-26.

4. Moreira MVF, Ribeiro LA, Alves EE, Neuenschwander FC, Rabelo RR, Filho UL; et al. Há relação entre custos hospitalares e tempo porta-balão? Rev Bras Cardiol Invas. 2015; 23(3):195-200.

5. Campos HAB, MVF Moreira, EE Alves, R Wang, ACM Bedeti, FC Neuenschwander, et al. Impacto da adoção de processos de trabalho hospitalares na redução do tempo porta-balão. Rev Bras Cardiol Invas. 2017;25(1-4):7-11.

6. Chao CC, Chen YC, Shih CM, Hou SK, Seethala RR, Aisiku IP, et al. Smartphone transmission of electrocardiography images to reduce time of cardiac catheterization laboratory activation. J Chin Med Assoc.. 2018;81(6):505-10.

7. Chen FC, Lin YR, Kung CT, Cheng CI, Li CJ. The Association between Door-to-Balloon Time of Less Than 60 Minutes and Prognosis of
Statistical analysis: Amoras TSG, Menezes CR. Writing of the manuscript: Amoras TSG, Menezes CR, Zaninotto $\mathrm{CV}$, Rodrigues TB, Tavares RS. Critical revision of the manuscript for intellectual content: Amoras TSG, Menezes CR, Zaninotto CV, Rodrigues TB, Tavares RS.

\section{Potential Conflict of Interest}

No potential conflict of interest relevant to this article was reported.

\section{Sources of Funding}

There were no external funding sources for this study.

\section{Study Association}

This article is part of the thesis of master submitted by Tárcio Sadraque Gomes Amoras, from Universidade do Estado do Pará and Fundação Hospital de Clínicas Gaspar Vianna.

\section{Ethics Approval and Consent to Participate}

This study was approved by the Ethics Committee of the Fundação Hospital de Clínicas Gaspar Vianna under the protocol number 82951718.3.0000.0016. All the procedures in this study were in accordance with the 1975 Helsinki Declaration, updated in 2013. Informed consent was obtained from all participants included in the study.

Patients Developing ST Segment Elevation Myocardial Infarction and Undergoing Primary Percutaneous Coronary Intervention. BioMed Res Int. 2017;2017:1910934.

8. Byrne J. Reducing time to reperfusion for ST elevation myocardial infarction patients by a simple process change in the Emergency Department. BMJ Qual Improv Rep.2014;3(1):pii u204753.v.2063 [internet]. 2014 jun [acesso em 23 dezembro 2018]; 3 (1). Disponível em: https://bmjopenquality.bmj.com/content/3/1/u204753.w2063.full.pdf.

9. Oliveira LS, Costa DN, Oliveira DML, Almeida HOC, Mendonça IO. Indicadores de qualidade nos serviços de urgência hospitalar. Ciências Biológicas Saúde Unit.2018;4(3):173-88.

10. Silveira CLG, Melo VFC, Barreto AJR. Atenção à saúde do homem na atenção primária em saúde: uma revisão integrativa.Rev enferm UFPE (on line) ;2017;11(supl.3):1528-9.

11. Brunori EHFR, Lopes CT, Cavalcante AMRZ, Santos VB, Lopes JL, Barros ALBL. Associação de fatores de risco cardiovasculares com as diferentes apresentações da síndrome coronariana aguda. Ver Latino Am Enfermagem. 2014;22(4):538-46.

12. Costa MO. Perfil epidemiológico e fatores de risco de pacientes com diagnóstico de infarto agudo do miocárdio em um hospital de referência cardiológica em Belém-PA [Monografia]. Belém: Universidade do Estado do Pará; 2014

13. Martin RSS, Godoy I, Franco RJS, Martin LC, Martins AS. Influência do nível socioeconômico sobre os fatores de risco cardiovascular. J Bras Med. 2014; 102(2):34-7. 
14. Dharma S, Siswanto BB, Firdaus I, Dakota I, Andriantoro H, Wardeh AJ, et al. Temporal Trends of System of Care for STEMI: Insights from the Jakarta Cardiovascular Care Unit Network System. PLoS One. 2014;9(2):e86665.

15. Coyne CJ, Testa N, Desai S, Lagrone J, Chang R, Zheng L, et al. Improving Door-to-balloon Time by Decreasing Door-to-ECG time for Walk-in STEMI Patients. West J Emerg Med. 2015; 16(1):184-9.

16. Chen H, Liu J, Xiang D, Qin W, Zhou M, Tian Y, et al. Coordinated Digital-Assisted Program Improved Door-to-Balloon Time for Acute Chest Pain Patients. Int Heart J. 2016;57(3):310-6.

17. Nguyen B, Fennessy M, Leya F, Nowak W, Ryan M, Freeberg S, et al. Comparison of Primary Percutaneous Coronary Intervention in Patients With ST-Elevation Myocardial Infarction during and Prior to Availability of na In-House STEMI System: Early Experience and Intermediate Outcomes of the HARRT Program for Achieving Routine D2B Times $<60$ Minutes. Cathet Cardiovasc Interv. 2015;86(2):186-92

18. Mentias A, Raza MQ, Barakat AF, Youssef D, Raymond R, Menon $\mathrm{V}$, et al. Effect of Shorter Door-to-Balloon Times Over 20 Years on Outcomes of Patients With Anterior ST-Elevation Myocardial Infarction Undergoing Primary Percutaneous Coronary Intervention. Am J Cardiol. 2017;120(8):1254-9.

19. Santos FG, Campanharo CRV, Lopes MCBT, Okuno MFP, Batista REA, et al. Avaliação da qualidade do atendimento ao paciente com síndrome coronariana aguda no serviço de emergência. Ver Eletrr Enf. 2015;17(4):1-9.

20. Tsukui T, Sakakura K, Taniguchi Y, Yamamoto K, Wada H, Momomura $\mathrm{S}$, et al. Determinants of short and long door-to-balloon time in current primary percutaneous coronary interventions. Heart and Vessels . 2018;33(5):498-506

21. Puymirat E, Caudron J, Steg PG, Lemesle G, Cottin Y, Coste P, et al Prognostic impact of non-compliance with guidelines-recommended times to reperfusion therapy in ST-elevation myocardial infarction. The FAST-MI 2010 registry. Eur Heart J Acute Cardiovasc Care. 2017;6(1):26-33

22. Mendes SIR. A pessoa com enfarte agudo do miocárdio no serviço de urgência: da triagem ao tratamento [Dissertação].Coimbra: Escola Superior de Enfermagem de Coimbra; 2017.

23. Chen KC, Yin WH, Young MS, Wei J. In-Hospital Tele-ECG Triage and Interventional Cardiologist Activation of the Infarct Team for STEMI Patients is Associated with Improved Late Clinical Outcomes. Acta Cardiol Sin.2016;32(4):428-38.

24. Sardi GL, Loh JP, Torguson R, Satler LF, Waksman R. Real-time, twoway interaction during ST-segment elevation myocardial infarction management improves door-to-balloon times. Cardiovas Revasc Med.2014;15(5):263-8.

25. Takeuchi I, Fujita H, Yanagisawa T, Sato N, Mizutani T, Hattori J, et al Impact of Doctor Car With Mobile Cloud ECG in Reducing Door-toBalloon Time of Japanese ST-Elevation Myocardial Infarction Patients. Int Heart J. 2015;56(2):170-3.

26. Kawakami S, Tahara Y, Noguchi T, Yagi N, Kataoka Y, Asaumi Y, et al Time to Reperfusion in ST-Segment Elevation Myocardial Infarction Patients With vs. Without Pre-Hospital Mobile Telemedicine 12-Lead Electrocardiogram Transmission. Circulation J.2016;80(7):1624-33. 